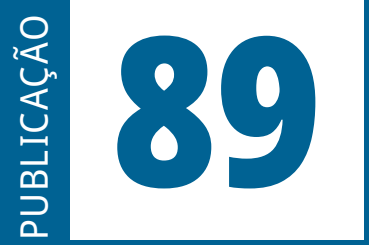

ISSN: 0101-9562

ISSN ELETRÔNICO: 2177-7055

SEQÜÊNCIA

Publicação do

Estudos jurídicos

e políticos

Programa de Pós-Graduação em Direito da UFSC

VOLUME 42 - ANO 2021 
SEQUÊNCIA - ESTUDOS JURÍDICOS E POLÍTICOS é uma publicação temática e de periodicidade quadrimestral, editada pelo Programa de Pós-Graduação Stricto Sensu em Direito da Universidade Federal de Santa Catarina - UFSC.

SEQUÊNCIA - ESTUDOS JURÍDICOS E POLÍTICOS is a thematic publication, printed every four months, edited by the Program in law of the Federal University of Santa Catarina - UFSC.

Versão eletrônica: http://www.periodicos.ufsc.br/index.php/sequencia

A publicação é indexada nas seguintes bases de dados e diretórios/

The Publication is indexed in the following databases and directories:

Base OJS

Base PKP

CCN (Catálogo Coletivo Nacional)

Dialnet

DOAJ (Directory of Open Access Journals)

EBSCOhost

Genamics Journalseek

ICAP (Indexação Compartilhada de Artigos de Periódicos)

Latindex

LivRe!

OJS
PKP
Portal de Periódicos UFSC
Portal do SEER
ProQuest
SciELO
Sherpa/Romeo
Sumarios.org
ULRICH'S
vLex

Ficha catalográfica

Seqüência: Estudos jurídicos e políticos. Universidade Federal de Santa Catarina.

Programa de Pós-Graduação em Direito. n.1 (janeiro 1980)-.

Florianópolis: Fundação José Boiteux. 1980-.

Publicação contínua

Resumo em português e inglês

Versão impressa ISSN 0101-9562

Versão on-line ISSN 2177-7055

1. Ciência jurídica. 2. Teoria política. 3. Filosoia do direito. 4. Periódicos.

I. Universidade Federal de Santa Catarina. Programa de Pós-graduação em

Direito

CDU 34(05)

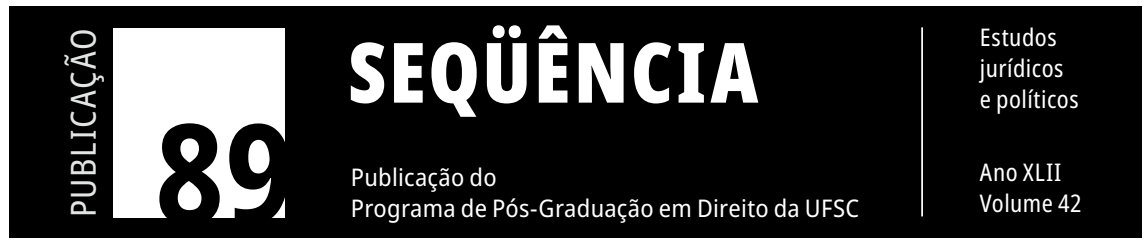




\title{
Direito de propriedade: condições de igualdade e funcionamentos
}

\section{Property right: conditions of equality and functioning}

\author{
João Daniel Macedo Sá ${ }^{1}$ \\ ${ }^{1}$ Universidade Federal do Pará, Belém, Brasil
}

RESUMO: O presente artigo aborda o tema do direito de propriedade a partir do pensamento de Amartya Sen e sua correlação com a pobreza. O objetivo é relacionar o papel que a propriedade desempenha no âmbito do desenvolvimento humano. Como proposta, o trabalho pretende analisar em que medida a abordagem das "capacidades" pode fundamentar a defesa do direito de propriedade. Para tanto, inicialmente analisa-se a teoria das capacidades de Sen. Em seguida, verifica-se a possível relação entre propriedade, pobreza e desenvolvimento humano. A metodologia do trabalho baseou-se em pesquisa teórica, com levantamento bibliográfico. Para justificar e argumentar sobre as hipóteses levantadas foi utilizado o método dedutivo. Pretende-se, ao fim, demonstrar que o direito de propriedade representa um papel instrumental importante para o desenvolvimento humano, na medida em que constitui um meio para expansão das liberdades.

PalAVRAS-CHAVE: Direitos de propriedade - Abordagem das capacidades - Amartya Sen.

ABSTRACT: This article addresses the theme of property rights based on Amartya Sen's thinking and its correlation with poverty. The objective is to relate the role that property plays in the context of human development. As a proposal, the work intends to analyze to what extent the capacity approach can support the defense of property rights. To do so, initially we examine Sen's capacity theory. Then, we verify the possible relationship between property, poverty and human development. The methodology of the work was based on theoretical research, with bibliographic survey. In order to justify and argue about the hypotheses raised, the 
deductive method was used. We intend, in the end, to demonstrate that the right of property represents an important instrumental role for human development, insofar as it constitutes a means for the expansion of freedoms.

KeYwords: Property rights - Capability Approach - Amartya Sen.

\section{INTRODUÇÃO}

O modelo de propriedade privada compreendido nos principais ordenamentos jurídicos da sociedade contemporânea se baseia na tradição liberal, inaugurada durante o período iluminista.

Referido modelo, quando juridicamente considerado, insere o direito de propriedade na base da concepção moderna de direitos humanos, tratando-o como um direito fundamental, que protege a liberdade de cada indivíduo na sociedade em diversos aspectos.

Pipes (2001) atribui ao século XVII o desenvolvimento da visão de direito natural da propriedade, como sendo uma decorrência dos conflitos entre a coroa e o parlamento inglês sobre seus respectivos poderes e, especialmente, sobre o direito do rei para cobrar impostos sem o consentimento do parlamento. Nesse período, a riqueza fundiária da coroa passou para as mãos do Estado, que vendeu uma boa parte a particulares ${ }^{1}$.

Entretanto, apesar de ainda ser tratado por diversos autores como um direito natural (um direito pré-político), referida ideia não mais se

\footnotetext{
"Durante essa época turbulenta, o termo 'propriedade' sofreu uma metamorfose, revolucionária em suas implicações, passando a significar não apenas objetos materiais, mas tudo a que o indivíduo tinha um direito natural de reivindicar como seu. Esta noção foi prefigurada no pensamento medieval, que definia o conceito de suum como incluindo tudo o que pertencesse ao homem em virtude do seu direito inerente ou 'natural' e que envolvia, junto com os seus bens materiais, também a sua vida e a sua liberdade. A fórmula latina suum cuique tribuere, traduzida para o latim por Platão e popularizada por Cícero, foi citada por Santo Tomás de Aquino para definir justiça ('o desejo constante e perpétuo de dar a cada um o que é seu'). Thomas Hobbes, em meados do século XVII, traduziu a frase como 'dando a cada um o que é seu' ou suum por 'propriedade"”(PIPES, 2001, p. 52).
} 
sustenta. Como demonstram Liam Murphy e Thomas Nagel (2005, p. 51) essa concepção estava assentada num conjunto de pressupostos irrefletidos e geralmente aceitos que não resistem a um exame mais acurado, sendo mais coerente que o direito de propriedade seja visto como algo que depende do sistema jurídico que o define. Isso quer dizer que a propriedade é convencional.

Nesse sentido, afirmar que esse direito é convencional significa também assumir que toda propriedade é uma criação do sistema jurídico. Significa, também, assumir que a justificação e defesa do modelo da propriedade privada contemporânea não retratam apenas uma simples relação entre coisas e pessoas.

A propriedade abrange, como destaca Waldron (1985, p. 314), um complexo de relações que diferem consideravelmente em seu caráter e efeito, gerando como consequência uma dificuldade de sua definição em cada sistema jurídico, e a necessidade de uma compreensão mais dinâmica do instituto.

Por isso, cabe destacar que o conceito de propriedade pode se referir a diversos conteúdos ou a uma multiplicidade de estatutos que influem na relação entre os diferentes objetos e sujeitos sobre os quais pode recair o domínio (sobre as coisas corpóreas) e a titularidade dos direitos (SÁ, 2019, p. 243).

Não obstante, esse nível de proteção (propriedade $>$ direito fundamental $>$ direitos humanos) carrega consigo uma ideia contemporânea de que o sistema da propriedade privada tem como característica inerente a desigualdade (propriedade $>$ liberdade de acumulação $>$ desigualdade).

Tomando por base o referencial da filosofia política, em especial a teoria da justiça, segundo a formulação Rawlseana, exsurge a premissa de que as desigualdades só podem ser justificadas se as pessoas que se encontram em pior situação sob esse sistema estiverem em melhor situação do que estariam sob uma distribuição uniformemente igualitária de bens (RAwLs, 2008, p. 376).

O presente ensaio, cujo enfoque se dá a partir do sistema jurídico brasileiro, procura relacionar o papel que a propriedade desempenha no 
âmbito do desenvolvimento humano. E um dos principais referenciais teóricos que discute a questão do desenvolvimento humano é Amartya Sen.

Por isso, o artigo está orientado pela seguinte pergunta: como a abordagem das capacidades proposta por Amartya Sen (1988; 2000; 2008 ; 2011) se compatibiliza com uma defesa da propriedade privada no sistema jurídico brasileiro? De que modo essa defesa da propriedade se relaciona com a desigualdade? E qual a relação dessa proteção (da propriedade privada) no âmbito do desenvolvimento humano?

É necessário destacar que a amplitude do conceito de propriedade que será adotado representa todo tipo de riqueza e patrimônio que podem ser transmitidos, comprados ou vendidos. Representa o conjunto de ativos não humanos que podem ser adquiridos, vendidos e comprados.

Para Piketty (2014, p. 51), essa definição integra o conceito de capital e compreende, especificamente, "o conjunto formado pelo capital imobiliário (imóveis, casas), utilizado para moradia, e pelo capital financeiro e profissional (edifícios e infraestrutura, equipamentos, máquinas, patentes etc.), usado pelas empresas e pela administração pública”.

A metodologia do trabalho baseou-se em pesquisa teórica, com levantamento bibliográfico. Para justificar e argumentar sobre as hipóteses levantadas foi utilizado o método dedutivo.

Seguindo a lógica de análise, o trabalho se desenvolve em dois capítulos, sendo o primeiro dedicado à análise da teoria das capacidades de Amartya Sem, com aporte teórico inicial de John Rawls. O capítulo seguinte aborda a relação entre propriedade, pobreza e desenvolvimento humano.

\section{RAWLS VS. SEN: A LIBERDADE COMO RESULTADO DA IGUALDADE DE CAPACIDADES PARA REALIZAR FUNCIONAMENTOS}

A justiça, conforme concebida por Rawls (2008, p. 8), tem como objeto principal a estrutura básica da sociedade, que representa o locus 
onde é definido o modo como as principais instituições sociais distribuem os direitos e os deveres fundamentais e a divisão de vantagens provenientes da cooperação social.

Para Cittadino (2004, p. 99), Rawls parte do pressuposto de que há uma ideia intuitiva implícita na cultura democrática que descreve a sociedade como um sistema equitativo de cooperação social entre pessoas livres e iguais, que têm a capacidade de ter uma concepção de bem e um senso de justiça.

Por isso, a justiça, na visão Rawlsiana, deve se ocupar da distribuição dos bens necessários à busca de praticamente qualquer fim. Esses bens, chamados de bens primários sociais, correspondem, por exemplo, às liberdades, oportunidades, renda, riqueza além do auto respeito.

Segundo essa formulação, as instituições sociais que regulam a propriedade estão abrangidas na estrutura básica da sociedade. Essas instituições representam o conjunto de normas públicas que define cargos e posições, direitos e deveres, poderes e imunidades (RAwls, 2008, p. 66).

Rosas (2011, p. 25) entende que, além dos arranjos no domínio da propriedade, as instituições sociais correspondem à Constituição, às principais leis e, ainda, ao conjunto das instituições que asseguram os direitos na saúde, na educação, na seguridade social, entre outros.

O direito de propriedade é considerado por Rawls um bem primário, ou seja, uma liberdade fundamental. Por isso, a propriedade está protegida pelos princípios de justiça, em especial o primeiro. Isso justifica, do ponto de vista teórico, que o mesmo seja considerado um direito fundamental (SÁ, 2019, p. 261).

Segundo Brito Filho (2014, p. 245), os bens primários equivalem aos direitos fundamentais: são "todos os fundamentais, indicados a partir do artigo 5. ${ }^{\circ}$, Constitucional, em conjunto que inclui os direitos e garantias individuais e coletivos, os direitos sociais, os direitos de nacionalidade e os direitos políticos ${ }^{2}$.

2 No mesmo sentido é o entendimento de Ramos (2005, p. 19). 
Conforme será demonstrado ao longo deste trabalho, Amartya Sen aceita as proposições de Rawls, mas sustenta que o importante não é que todos tenham os mesmos bens, e sim que tenham as mesmas capacidades.

Álvaro de Vita (2008, p. 91) sugere que Amartya Sen efetivamente não propôs uma nova teoria da justiça, alternativa à de Rawls, já que a sua abordagem das capacidades seria, em vários aspectos, dependente das estruturas normativa e ideológica da teoria Rawlseana.

Em suas análises, Sen (2008, p. 43) defende que todos os trabalhos posteriores ao de John Rawls discutem a igualdade em alguma medida. No entanto, destaca que mais importante do que discutir "por que a igualdade" é sabermos "de quê igualdade" estamos tratando.

No caso de Rawls, a crítica de Sen é direcionada à atenção atribuída à igual liberdade e igualdade na distribuição de bens primários. A preocupação de Sen está mais vinculada aos meios que as pessoas dispõem para buscarem seus fins.

Sen (2008, p. 142) afirma que essa completa prioridade atribuída ao princípio da liberdade em relação a outros princípios de justiça é insuficiente se considerarmos que "a igualdade de liberdade para buscar nossos fins não pode ser gerada pela igualdade na distribuição de bens primários”. Defende, nesse sentido, a necessidade de examinarmos as variações interpessoais que ocorrem da transformação de bens primários em respectivas capacidades para que um indivíduo possa buscar seus fins e objetivos.

Sen argumenta, ainda, que se a preocupação da justiça deve ser com a igualdade da liberdade, não é mais adequado exigir a igualdade de seus meios do que a igualdade de seus resultados. A liberdade se relaciona com ambos, mas não coincide com nenhum, podendo as ideias de Rawls serem interpretadas para reorientar a análise da igualdade e da justiça em direção às liberdades abrangentes realmente desfrutadas.

Para analisar a desigualdade é importante ter em mente o espaço de avaliação, que é determinado pelo foco de análise em que se dá a 
discussão. Esse foco pode se basear em variáveis diferentes, como por exemplo, nas rendas, riquezas, utilidades, liberdades, direitos e ou qualidades de vida que as pessoas têm.

Essas diferenças de foco são importantes quando se tem em mente a diversidade humana, pois as pessoas, mesmo que igualadas em determinado espaço (como em relação à renda ou riqueza), não necessariamente serão iguais nos outros.

Isso quer dizer que a diversidade dos indivíduos impede que sejam igualados a partir dos meios (daquilo que Rawls denominou como sendo os bens primários), pois, ainda que isso ocorresse, tais indivíduos não necessariamente teriam as mesmas condições de utilizá-los (ou seja, de converter isso em liberdades) por conta de suas próprias características intrínsecas, tais como idade, sexo, propensão a doenças e habilidades gerais, dentre outras (Sen denomina essas variações de problemas de conversão).

Quando trata da liberdade de escolha, Sen (2008, p. 69) argumenta que a posição social de uma pessoa pode ser julgada sob duas perspectivas, que se traduzem em termos de desigualdade.

A primeira diz respeito à realização de fato conseguida, que se liga ao que as pessoas conseguem fazer ou alcançar. Existem diferentes modos de julgar a realização como, por exemplo, por meio da utilidade (prazeres obtidos ou satisfeitos), pela opulência (rendas ganhas ou consumos usufruídos) ou por meio da qualidade de vida (medidas de padrões de vida).

A segunda manifesta-se pela liberdade para realizar, que se liga à oportunidade real que as pessoas têm para fazer ou alcançar aquilo que valorizam.

A questão central para Amartya Sen é saber o que as pessoas efetivamente podem fazer com esses meios, já que os bens primários que uma pessoa detém podem ser indicadores bastante imperfeitos da liberdade que essa pessoa realmente desfruta para fazer algo. Desse modo, o autor faz seu recorte em torno daquilo que denominou “capacidades” e suas correlações com o bem-estar (SEN, 2008, p. 79). 
Para Sen, o bem-estar representa a qualidade do estado das pessoas. A vida das pessoas está cercada por um conjunto de funcionamentos que compreendem estados e ações.

A capacidade para realizar funcionamentos equivale às várias combinações de estados e ações que uma pessoa pode realizar, ou seja, reflete a liberdade da pessoa para levar um tipo de vida ou outro. Os conjuntos capacitários, em sentido mais amplo, refletem a liberdade da pessoa para escolher dentre vidas possíveis.

A relevância da capacidade de uma pessoa para seu bem-estar está relacionada a duas considerações distintas e interrelacionadas: 1) a liberdade de bem-estar representa a capacidade para realizar funcionamentos, vistos enquanto oportunidades reais para ter bem-estar (nesse sentido, a liberdade pode ser vista como intrinsecamente importante para uma boa estrutura social. A liberdade, nesse sentido, é um fim em si mesmo); 2) o bem-estar realizado depende da capacidade para realizar funcionamentos. Por isso, a possibilidade de escolha do indivíduo é por si só algo que deve ser valorizado.

A ideia de capacidade é orientada para a "aptidão real das pessoas para escolher viver diferentes tipos de vida a seu alcance" (SEN, 2011, p. 271). Essa abordagem da capacidade difere da abordagem de Rawls, pois a capacidade reflete a liberdade para buscar os funcionamentos (que são os elementos constitutivos do bem-estar), à medida que decisões e escolhas também são componentes daquilo que Sen entende por bem-estar.

A abordagem da capacidade de realizar funcionamentos não pode ser vista como exercício do tipo tudo ou nada quando se trata de comparações interpessoais de bem-estar. Mesmo que não haja acordo completo sobre os pesos relativos a serem atribuídos a diferentes funcionamentos, ter mais de cada funcionamento ou capacidade relevante é uma clara melhora, e isto pode ser determinado sem que se espere chegar a um acordo sobre os pesos relativos a serem atribuídos a diferentes funcionamentos e capacidades.

Se a capacidade representa reflexo da liberdade para realizar funcionamentos valiosos, e se os funcionamentos são constitutivos 
do bem-estar, então a capacidade representa a liberdade para realizar bem-estar (SEN, 2008, p. 89).

Sen argumenta que não há diferença entre focalizar funcionamentos ou capacidades, pois uma combinação de funcionamentos representa um ponto em determinado espaço, enquanto a capacidade é um conjunto de tais pontos.

O que o autor está defendendo é que a liberdade de escolha assume importância direta para a qualidade de vida e bem-estar das pessoas, pois mais liberdade de escolha torna disponível um número maior de alternativas. A liberdade representa, de algum modo, o potencial dos indivíduos para conseguir aquilo que valorizam. Exercer o controle sobre a escolha garante aos indivíduos mais poder para levar a vida que quiserem.

Para Sen (2008, p. 118), a liberdade é uma das mais influentes ideias sociais, e sua relevância para a análise da igualdade e da justiça é forte e de grande alcance.

Quando avalia as desigualdades que as pessoas vivenciam em alguns casos, como por exemplo, por conta da incapacidade de escapar da fome, o autor considera que não estamos examinando apenas diferenças no bem-estar, mas também diferenças nas liberdades básicas valorizadas e apreciadas por todos.

É claro que aspectos ligados ao bem-estar são importantes se forem considerados problemas como os de seguridade social, de alívio da pobreza, de remoção de desigualdade econômica acentuada e, em geral, da busca da justiça social, pois "problemas de injustiça e desigualdade sociais entre diferentes classes e grupos relacionam-se fortemente com as disparidades do bem-estar", incluindo a liberdade que as pessoas desfrutam para realizar o bem-estar (SEN, 2008, p. 121).

Com essas considerações, Sen volta-se para os problemas da economia do bem-estar e das análises sobre desigualdade com enfoque na pobreza, pois entende que a avaliação da desigualdade deve levar em conta tanto a diversidade dos indivíduos como a pluralidade de espaços nos quais a desigualdade pode ser analisada. 
A igualdade entre as pessoas pode ser definida em termos de aproveitamentos ou em termos e insuficiências com relação aos valores máximos que cada uma pode respectivamente realizar. Para a "igualdade de aproveitamento de realizações", nós comparamos os níveis efetivos de realização. Para a "igualdade de insuficiências", comparam-se as insuficiências das realizações efetivas com relação às respectivas realizações máximas (SEN, 2008, p. 149).

O aspecto da diversidade deve ser considerado quando se verifica que a igualdade de aproveitamento pode ser difícil de realizar. É o que ocorre no caso de incapacidades graves, como, por exemplo, a capacidade para se locomover ou a capacidade de se manter com boa saúde.

Entretanto, mesmo quando não se pode dar a uma pessoa incapacitada a liberdade para desfrutar o mesmo nível do funcionamento em questão, existem bons argumentos, baseados na equidade, para que se tente maximizar seu menor potencial para realizar funcionamentos.

É a isso que a lógica rawlsiana do maximin conduz: "melhorar tanto quanto possível a situação dos que estão na pior situação" (SEN, 2008, p. 151). É nesse sentido que Sen afirma que boa parte do raciocínio de Rawls pode ser aplicado inclusive além de sua própria estrutura, quando se considera razões de equidade.

\section{PROPRIEDADE, POBREZA E DESENVOLVIMENTO HUMANO: A CONVERSÃO DE CAPITAL EM CAPACIDADES PARA REALIZAR FUNCIONAMENTOS}

A teoria de Amartya Sen, ao analisar a igualdade de capacidades, claramente tem implicações distributivas, o que justifica que seja discutida a relação existente entre essa abordagem e o direito de propriedade.

A conexão entre desigualdade e bem-estar social pode ser observada de diferentes maneiras, se mostrando razoável avaliar as desigualdades a partir da limitação dos conjuntos capacitários. 
Sen entendeu que isso era importante porque a indisponibilidade de recursos públicos para auxiliar na eliminação de severas privações não pode ensejar uma redefinição da própria pobreza, até porque isso gera a tentação nos governos de concentrarem seus esforços sobre os mais ricos entre os pobres, que seria o modo com que o número de pobres poderia mais facilmente ser reduzido. E esse é exatamente o tipo de abordagem que tanto Rawls como Sen combatem, pois traduz exatamente uma perspectiva utilitarista de política pública.

Nesse caso, argumenta Sen, é mais eficaz identificar aqueles que estão verdadeiramente privados no conjunto capacitário, de modo que o diagnóstico preceda a escolha de políticas em vez de simplesmente identificar a pobreza com a recomendação de alguma política:

Uma recomendação de política está condicionada à exequibilidade, mas o reconhecimento da pobreza tem de ir além disso. Pode-se argumentar que o primeiro passo consiste em diagnosticar a privação, e relacionado com ele, determinar o que devemos fazer se tivermos os meios. E então o próximo passo é fazer escolhas de políticas reais em conformidade com nossos meios. Neste sentido, a análise descritiva da pobreza tem de ser anterior à escolha de políticas (SEN, 2008, p. 171).

A pobreza é um fenômeno que pode ser analisado em várias dimensões, mas que se manifesta por uma incapacidade de buscar bem-estar. A adequação dos meios econômicos não pode ser julgada independentemente das possibilidades reais de conversão de rendas e recursos em capacidades para realizar funcionamentos.

(1) A pobreza pode sensatamente ser identificada em termos de privação de capacidades; a abordagem concentra-se em privações que são intrinsecamente importantes (em contraste com a renda baixa, que é importante apenas instrumentalmente).

(2) Existem outras influências sobre a privação de capacidades e, portanto, sobre a pobreza real - além do baixo nível de renda (a renda não é o único instrumento de geração de capacidades). 
(3) A relação instrumental entre baixa renda e baixa capacidade é variável entre comunidades e até mesmo entre famílias e indivíduos (o impacto da renda sobre as capacidades é contingente e condicional) (SEN, 2000, p. 109).

Outro aspecto central dessa consideração da desigualdade é a diferença entre grupos (categorias particulares) em detrimento da diferença entre indivíduos. Analisar a desigualdade de grupos se torna importante devido ao que isso representa para a desigualdade entre indivíduos situados em diferentes grupos.

Tome-se como exemplo a categoria "produtores rurais" e as desigualdades baseadas no direito de propriedade: podem existir diferenças de classe econômica, sexo, tamanhos das famílias, nível de escolarização e idade que certamente influenciarão o potencial que esse grupo ou categoria tem para se desenvolver (SÁ, 2018, p. 71).

Uma abordagem sobre questões de igualdade deve buscar enfoques diferenciados. Algo mais complexo do que análises baseadas puramente na igualdade de classe, propriedade e ocupação, pois existem outras diversidades que influenciam a vida que as pessoas podem levar e as liberdades de que podem desfrutar. Por exemplo, "mesmo se as desigualdades baseadas na posse de propriedade são completamente eliminadas, pode haver sérias desigualdades que surgem de diversidades nos potenciais (abilities) produtivos, necessidades e outras variações pessoais" (SEN, 2008, p. 188).

Esse aspecto das oportunidades é sério se pensarmos o problema na perspectiva do bem-estar. A igualdade de oportunidades já representa, por si só um avanço em termos políticos, mas a justiça, atrelada à noção de dignidade, como bem destaca Sarlet, vincula os direitos fundamentais simultaneamente como pressupostos de um espaço de liberdade real, mediante o reconhecimento da igualdade perante a lei e da igualdade de oportunidades, bem como por meio da outorga do direito à participação na conformação da comunidade e do processo político (SARLeT, 2015, p. 62). 
O ideal de uma sociedade que promove a igualdade de oportunidades só faz sentido se as pessoas, de fato, tenham condições de desenvolver suas capacidades. O que se quer mostrar, a partir de Sen, é que um acesso mais equitativo ao capital (renda, bens, etc), numa lógica de igualdade de oportunidades, não é necessariamente suficiente para garantir o pleno desenvolvimento humano.

Deepa Narayan aponta que a pobreza frequentemente é identificada com a falta do que é necessário para que as pessoas tenham um bem-estar material, como a falta de comida, moradia, terra e outros ativos (Narayan, 2000, p. 31).

Os estudos de Narayan privilegiam a visão dos próprios afetados sobre "o que é ser pobre". Na metodologia adotam-se avaliações participativas como forma de incorporar nas análises uma dimensão humana e social das populações entrevistadas. São estudos complementares aos de Sen e identificam a pobreza como um fenômeno multidimensional, que no aspecto material está ligado à falta de múltiplos recursos, que levam à fome e privação física. Nas áreas rurais, essas demandas tomam a forma de terras, juntamente com a posse de ativos que permitam o cultivo e uma boa colheita.

O desenvolvimento humano, da forma como é abordado por Sen, não é alcançado apenas pela posse de bens materiais específicos, pela satisfação de determinadas preferências subjetivas, ou até mesmo, por liberdades negativas. $\mathrm{O}$ desenvolvimento humano é marcado pelo atingimento de certas condições, que podem variar desde um nível básico, como ter alimentação adequada, até um nível mais complexo, tal como participar da vida política da comunidade, e pode ser experimentado sem que as pessoas necessariamente alcancem todos esses estágios (SEN, 2011, p. 267).

As pessoas podem discordar sobre quais são os recursos essenciais que possibilitam desfrutar de uma vida bem vivida. No entanto, algumas capacidades parecem incontroversas, sendo tão centrais que sua remoção também implica na remoção da própria dignidade humana.

Desse modo, é possível afirmar que essas capacidades, quando vinculadas às próprias condições mínimas para uma vida digna, 
expressam os próprios direitos humanos. Uma dessas capacidades, destacada por Nussbaum, é a capacidade de ter controle sobre o próprio ambiente material, o que significa, entre outros aspectos, "ser capaz de ter propriedade (terra e bens móveis), e ter direitos de propriedade em base igual a dos outros" (Nussbaum, 2011, p. 34).

Essa noção de liberdade tratada pela abordagem das capacidades claramente envolve pré-condições materiais. Um Estado que efetivamente se propõe a garantir direitos deve reconhecer normas para além dos aspectos formais, e terá de enfrentar questões relativas, por exemplo, à distribuição e redistribuição dos direitos de propriedade (Nussbaum, 2000, p. 227). E o fato é que algumas liberdades limitam outras: "A liberdade dos proprietários fundiários de manterem suas terras, algumas vezes limita a atuação do Estado em projetos que poderiam ser centrais para proporcionar muitas liberdades para os pobres" (Nussbaum, 2003, p. 44).

Não há nada de errado em pensar o direito de propriedade, em algumas dimensões, de maneira instrumental. Isso significa que uma norma, se estiver vinculada a implicações morais específicas, pode promover o desenvolvimento humano em vários aspectos importantes.

Tome-se como exemplo a discussão sobre tributação redistributiva (a exemplo do IPTU progressivo, tributação de grandes fortunas, etc.), a inclusão de proibições contra o uso nocivo da propriedade (a exemplo das disposições do Código Civil relativas a direitos de vizinhança) e limitações de caráter ambiental (leis que estimulem melhores práticas por meio de incentivos econômicos ou restrições administrativas).

Ao enfrentar a questão sobre qual deve ser o papel dos direitos de propriedade num sistema político e econômico, Scalet e Schmidtz (2010, p. 181) discutem dois modelos.

O primeiro seria um modelo de desenvolvimento baseado na cooperação e no crescimento econômico, que começa com uma ideia de mercado seguro e estável, onde as trocas são livres, onde a propriedade possibilita que as pessoas cooperem mutuamente na 
busca da geração de riqueza. O segundo se baseia na ideia de que o modelo de direitos de propriedade deve estar submetido a um controle político democrático, onde os cidadãos participam do processo que confere legitimidade às regras básicas da sociedade, incluindo direitos de propriedade.

Para os autores, o controle político é algo inevitável, e as sociedades mais bem-sucedidas integram os dois modelos, equilibrando essas visões por meio de uma democracia constitucionalmente limitada que permite um fluxo livre de capital. Esses modelos estão em tensão um com o outro, até certo ponto, já que o primeiro procura diminuir a influência da política sobre os direitos de propriedade, enquanto o segundo privilegia o controle direto.

Um Estado mais atuante não necessita abraçar um papel inexoravelmente interventivo, que seria incompatível com o compromisso básico de algumas liberdades fundamentais inerentes ao sistema democrático, a exemplo das liberdades civil e política, da liberdade econômica (liberdade de iniciativa), das liberdades de expressão e reunião, e das liberdades de consciência e de pensamento.

Em certos contextos, uma política regulatória poderia gerar o efeito inverso ao necessário para que as pessoas possam fazer outras escolhas boas e valiosas, ou seja, para que possam exercer sua liberdade para agir.

A partir dos pressupostos de Amartya Sen, defendemos que o papel do Estado deve ser o de implementar programas, ações e políticas públicas com vistas a obter resultados que incidam sobre o desenvolvimento humano, social, político e econômico dos seus cidadãos.

Numa sociedade justa, cada um deve receber igual parte dos benefícios que a sociedade proporciona e dos encargos que ela exige. A escolha crucial e valiosa sobre o exercício das capacidades permanece com o indivíduo e essa liberdade é em si parte do que representa o desenvolvimento humano.

A obrigação do Estado de apoiar e criar as estruturas sociais necessárias para a expansão das capacidades, e, portanto, a possibilidade de 
desenvolvimento humano, adquirem significado especial em relação à propriedade.

Sabemos que o direito de propriedade é inerentemente relacional e que, por causa dessa característica, os sujeitos proprietários (o titular do direito) devem necessariamente obrigações para com os outros. Um exemplo disso, incorporado no sistema jurídico brasileiro, é o conceito constitucional da função social da propriedade ${ }^{3}$.

A Constituição Federal de 1988 prescreve no inciso XXII do art. $5^{\circ}$, que o direito à propriedade privada é um direito fundamental. Também estabelece que este mesmo direito está condicionado ao cumprimento de uma função social (art. $5^{\circ}$, XXIII).

Entretanto, pode-se afirmar que o direito de propriedade caracterizado no art. $5^{\circ}$ da $\mathrm{CF} / 88$ é tratado de forma genérica, pois sua interpretação depende da análise dos direitos fundamentais em conjunto com os outros dispositivos constitucionais específicos ao tema da propriedade ${ }^{4}$.

A CF/88 não disciplina a possibilidade de restrições e regulamentações a direitos fundamentais, mas pode-se afirmar que estes apresentam um conteúdo essencial, que tem a ver: a) com aquilo que é protegido pelas normas de direitos fundamentais; b) com a relação daquilo que é protegido e suas possíveis restrições; e c) com a fundamentação tanto do que é protegido como de suas restrições (SILVA, 2014, p. 28).

O ponto em questão, está na avaliação, a partir do enfoque constitucional, sobre o dever (ou não!) do Estado brasileiro de criar

3 O condicionamento constitucional da propriedade ao cumprimento de uma função social tem seu início no Brasil, em 1934, quando o exercício do direito de propriedade passa expressamente a ser limitado pelo interesse social ou coletivo, caracterizando gradativa mudança de enfoque na preponderância do interesse público sobre o particular. Naquele período, prevalecia a ideia de que o Código Civil representava o centro da organização do direito privado, cujo sistema estava assentado na garantia da propriedade e da liberdade contratual.

4 Veja-se, nesse sentido, Comparato (1995) e Grau (2008), por todos. 
as estruturas sociais necessárias para a expansão das capacidades, e, portanto, do desenvolvimento humano. Na concepção aqui adotada, os direitos fundamentais constituem os direitos humanos universais, protegidos inclusive contra os eventuais abusos cometidos pelo Estado ${ }^{5}$.

A posição e o significado dos direitos fundamentais na Constituição de um Estado Democrático de Direito compreendem, desse modo, os limites normativos ao poder estatal, e constituem a condição de existência das liberdades de cada cidadão, que não podem ser violadas por leis e instituições injustas, mesmo que visem o bem-estar da coletividade (SÁ, 2018).

Em nossa visão, o ordenamento constitucional impõe que o primeiro papel da justiça é a preservação da liberdade do indivíduo em relação à vontade da maioria. Desse modo, como regra geral, quando uma intervenção indevida ocorrer, há uma prevalência dos direitos e garantias fundamentais contra os próprios interesses do Estado e de outros particulares.

Ao mesmo tempo, como afirma Rawls (2008), algumas desigualdades não são moralmente aceitáveis, de forma que nenhum indivíduo pode ter menos do que o mínimo necessário para sua sobrevivência, o que se expressa pelo conjunto mínimo de direitos necessários à preservação da dignidade da pessoa humana.

Para Piketty (2014, p. 555), o século XXI deverá enfrentar o desafio da regulação eficaz do capitalismo patrimonial globalizado, sob pena de que as desigualdades atuais de divisão da riqueza no mundo sejam cada vez maiores ${ }^{6}$.

Esse reconhecimento torna necessário garantir que a sociedade contribua para criar oportunidades de desenvolvimento das capacidades necessárias para a prosperidade dos seus cidadãos.

\footnotetext{
5 No caso de direitos sociais fundamentais (por exemplo, o direito à saúde), o que se protege, muitas vezes, não é o abuso, mas a falta de realização (a omissão) desses direitos pelo Estado.

6 Sua proposta reside na adoção de um imposto progressivo anual sobre o capital.
} 
Se todos precisam ter acesso a recursos para viabilizar sua sobrevivência física, o Estado deve garantir oportunidades adequadas para os indivíduos obterem as coisas de que precisam para funcionar como seres sociais, sem ao mesmo tempo minar os incentivos necessários para que as atividades produtivas se desenvolvam.

O reconhecimento do papel das liberdades no sistema político parece indicar que a garantia do direito de propriedade não deve ser vista como uma condição da justiça. A condição da justiça é a liberdade.

A propriedade apenas possibilita que o indivíduo tenha capacidade para realizar funcionamentos. A propriedade deve ser valorizada na medida em que constitui um meio para expansão das liberdades do indivíduo, ou seja, porque constitui um meio para que o indivíduo possa alcançar o desenvolvimento. Vista sob esse aspecto, a propriedade claramente representa uma liberdade instrumental.

A tradição liberal concebe a propriedade enquanto direito fundamental, um direito intrinsecamente importante. Não obstante, a abordagem das capacidades possibilita compreender que a propriedade também pode ser pensada como um bem de valor instrumental, apto a promover outros fins.

Não convém admitir que, pelo fundamento do valor intrínseco, o direito de propriedade seja considerado moralmente aceitável, ainda que resulte em consequências desastrosas. Como assevera Sen (1988, p. 593), não é recomendável que a avaliação moral de determinado direito seja desvinculada de suas prováveis consequências.

Ao fim e ao cabo, o que Sen defende é que o principal fim e meio do desenvolvimento é a expansão da liberdade, e que isso está diretamente relacionado com a qualidade de vida das pessoas.

O desenvolvimento se traduz inevitavelmente por um esforço cooperativo. A capacidade humana de cada indivíduo, para se desenvolver, exige certos bens materiais básicos e uma infraestrutura comum que dependem das contribuições de todos os membros da sociedade. Por isso, é necessário que existam sistemas formais de direitos de 
propriedade que possibilitem o controle político que torne possível o desenvolvimento humano.

\section{CONCLUSÃO}

Rawls defendeu que uma adequada concepção de justiça deve promover as liberdades fundamentais, a igualdade de oportunidades e a distribuição equitativa em termos econômicos.

Sen concorda com Rawls, na medida em que defende a igualdade das liberdades e a divisão da riqueza de acordo com regras institucionais, mas discorda que as pessoas devam ser igualadas na distribuição dos bens primários sociais (liberdades, oportunidades, renda e riqueza).

Pretendeu-se com o presente ensaio demonstrar que a abordagem de Sen pode ser vista como uma abordagem dos direitos humanos, à medida que as capacidades constituem os direitos fundamentais.

A pobreza é um fenômeno multidimensional, que se manifesta por uma incapacidade das pessoas de buscarem bem-estar, e no aspecto material está ligada à falta de múltiplos recursos, que levam à fome e privação física.

O direito de propriedade representa um papel instrumental importante para o desenvolvimento humano, na medida em constitui um meio para expansão das capacidades. A expansão das capacidades assume importância direta para a qualidade de vida e o bem-estar das pessoas, pois aumenta a liberdade das pessoas para levarem a vida que quiserem.

Se entendermos que no contexto brasileiro as desigualdades decorrentes do capital, tomando como exemplo o acesso a terras cultiváveis (em áreas rurais) ou o acesso à moradia digna (em áreas urbanas), representam um fator constitutivo da pobreza que afeta o conjunto capacitário das pessoas que vivem com severa privação, o problema decorrente dessa constatação será identificar quais políticas estão mais adequadas aos meios dos quais dispomos para enfrentar esse problema. 
Por isso, defendemos que o Estado tem a obrigação de apoiar e criar as estruturas sociais necessárias para a expansão das capacidades de seus cidadãos, sempre tendo em vista o papel instrumental que a propriedade desempenha como condição necessária à liberdade das pessoas para levarem a vida que quiserem.

\section{REFERÊNCIAS}

BRITO FILHO, José Cláudio Monteiro de. A justiça como equidade, de John Rawls, como uma teoria suficiente par justificar a concessão adequada dos direitos fundamentais sociais. In: DIAS, Jean Carlos; GOMES, Marcus Alan de Melo (Orgs.). Direito e desenvolvimento. 1ed. Rio de Janeiro/ São Paulo: Forense / Método, 2014.

BOBBIO, Norberto; MATTEUCCI, Nicola; PASQUINO, Gianfranco. Dicionário de política. 13. ed. Brasília: Ed. da UnB, 2007.

CITTADINO, Gisele. Pluralismo, direito e justiça distributiva: elementos de filosofia constitucional contemporânea. 3 ed. Rio de Janeiro: Lumen Juris, 2004.

COMPARATO, Fabio Konder. Função social da propriedade dos bens de produção. In: Direito empresarial: estudos e pareceres. São Paulo: Saraiva, 1995.

FLEISCHACKER, Samuel. Uma breve história da justiça distributiva. Tradução de Álvaro de Vita. São Paulo: Martins Fontes, 2006.

GRAU, Eros Roberto. A Ordem econômica na Constituição de 1988: (Interpretação e crítica). 13. ed., rev. e atual. São Paulo: Malheiros, 2008.

MURPHY, Liam; NAGEL, Thomas. O mito da propriedade: os impostos e a justiça. Trad. Marcelo Brandão Cipolla. São Paulo: Martins Fontes, 2005.

NUSSBAUM. Martha C.. Capabilities as fundamental entitlements: Sen and social justice. Feminist Economics, v. 9, n. 2-3, p. 33-59, 2003. Disponível em: http://www.ccee.edu.uy/ensenian/catgenyeco/Materiales/2011-08-10\%20M6\%20-\%20Nussbaum\%282003\%29CapabilitiesAsFundamental.pdf. Acesso em: 27 Out. 2020.

NUSSBAUM. Martha C. Creating capabilities: the human development approach. England: Harvard University Press, 2011. 
NUSSBAUM. Martha C. Fronteiras da justiça: deficiência, nacionalidade, pertencimento à espécie. Tradução de Susana de Castro. São Paulo: Martins Fontes, 2013.

NARAYAN, Deepa. Voices of the poor: Can anyone hear us? Washington, D.C.: The World Bank, Oxford University Press, 2000.

PIKETTY, Thomas. O capital no século XXI. Tradução Monica Baumgarten de Bolle. Rio de Janeiro: Intrínseca, 2014.

PIPES, Richard. Propriedade e liberdade. Tradução de Luiz Guilherme B. Chaves e Carlos Humberto Pimentel Duarte da Fonseca. Rio de Janeiro: Record, 2001.

RAMOS, André de Carvalho. Teoria geral dos direitos humanos na ordem internacional. Rio de Janeiro: Renovar, 2005.

RAWLS, John. Uma teoria da justiça. 3 ed. Tradução Jussara Simões. São Paulo: Martins Fontes, 2008.

ROSAS, Joao Cardoso. Concepções da justiça. Lisboa: Edições 70, 2011. Coleção O Saber da Filosofia, n. 41.

SÁ, João Daniel Macedo. Direito de propriedade: uma análise do papel da propriedade rural no contexto da justiça distributiva. Rio de Janeiro: Lumen Juris, 2018.

SÁ, João Daniel Macedo. Direito de Propriedade e Teoria da Justiça: a defesa da propriedade na justiça distributiva a partir da concepção de John Rawls. Sequência: Estudos Jurídicos e Políticos, Florianópolis, v. 41, n. 82, p. 242264, ago. 2019. ISSN 2177-7055. Disponível em: https://periodicos.ufsc. br/index.php/sequencia/article/view/2177-7055.2019v41n82p242. Acesso em: 27 Out. 2020.

SCALET, Steven; SCHMIDTZ, David. Famine, Poverty, and Property Rights. In: MORRIS, Christopher W. Amartya Sen. New York: Cambridge University Press, 2010.

SARLET, Ingo Wolfgang et. al. Curso de direito constitucional. 3 ed. São Paulo: RT, 2014.

SEN, Amartya. A ideia de justiça. Tradução Denise Bottmann, Ricardo Doninelli Mendes. São Paulo: Companhia das Letras, 2011.

SEN, Amartya. Desigualdade reexaminada. Tradução Ricardo Donielli Mendes. 2 ed. Rio de Janeiro: Record, 2008. 
SEN, Amartya. Desenvolvimento como liberdade. Tradução Laura Teixeira Motta, Ricardo Doninelli Mendes. São Paulo: Companhia das Letras, 2000 .

SEN, Amartya. Property and Hunger. In: Economics and Philosophy. v. 4. Reino Unido. Cambridge Journals Online, 1988. p. 57-68. Disponível em: http://users.manchester.edu/Facstaff/SSNaragon/Online/texts/425/ Sen,\%20PropertyHunger.pdf. Acesso em: 01 Out. 2020.

SILVA, Virgílio Afonso da. Direitos fundamentais: conteúdo essencial, restrições e eficácia. 2 ed. $3^{a}$ tir. São Paulo: Malheiros, 2014.

VITA, Álvaro de. O liberalismo igualitário: sociedade democrática e justiça internacional. São Paulo: Martins Fontes, 2008.

WALDRON, Jeremy. What is private property? Oxford J. Legal Stud. 313, 1985.

\section{JOÃO DANIEL MACEDO SÁ}

Professor da Universidade Federal do Pará. É doutor em direito pela Universidade Federal do Pará. Tem experiência na área de Direito, com ênfase em Direito Civil e Direito Ambiental, atuando principalmente com o direito de propriedade sob o enfoque da teoria da justiça e na responsabilidade civil, com enfoque em danos ambientais. Tem interesse nas linhas de pesquisa em Teoria do Direito, Filosofia Política e Filosofia do Direito.

Endereço profissional: R. Augusto Corrêa, 01 - Guamá, Belém PA, 66075-110, Brasil.

ORCID ID: http://orcid.org/0000-0003-3747-080X

E-MAIL: jdaniel_sa@yahoo.com

Recebido: 28/10/2020

Aceito: 18/01/2022 


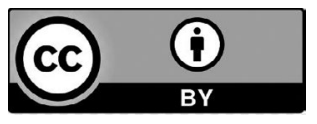

Este trabalho está licenciado sob uma licença Creative Commons Attribution 4.0 International License.

Autores e autoras cedem à Revista Sequência direitos exclusivos de primeira publicação, ficando o trabalho licenciado sob a Creative Commons Attribution 4.0 International License. A licença autoriza que terceiros remixem, adaptem e ou criem a partir do trabalho publicado, indicando o crédito ao trabalho original e sua publicação inicial. Os autores têm permissão para assumir contratos adicionais em separado, com distribuição não exclusiva da versão publicada na Revista Sequência, indicando, de todo modo, a autoria e publicação inicial neste periódico. 